\title{
O INHANDUVÁ (PROSOPIS AFFINIS SPRENG.) NO RIO GRANDE DO SUL. 5 - OCORRÊNCIA NATURAL NA VÁRZEA DO RIO SANTA MARIA, ROSÁRIO DO SUL ${ }^{1}$
}

\author{
FABIANO DA SILVA ALVES² JOSÉ NEWTON CARDOSO MARCHIORI ${ }^{3}$
}

\section{RESUMO}

A ocorrência natural de Prosopis affinis Spreng. (Fabaceae) é estendida ao município de Rosário do Sul, Rio Grande do Sul, com a presente descrição de fragmentos remanescentes de parques de inhanduvá na planície aluvial do rio Santa Maria, uns $15 \mathrm{~km}$ ao sul da cidade.

Palavras-chave: Prosopis affinis, Fitogeografia, Rosário do Sul, Rio Grande do Sul.

\section{SUMMARY}

[Prosopis affinis Spreng. in Rio Grande do Sul state, Brazil. 5 - Natural occurrence on Santa Maria river's flood plain, municipality of Rosario do Sul, Brazil].

The natural occurrence of Prosopis affinis Spreng. (Fabaceae) is extended to the municipality of Rosario do Sul (Rio Grande do Sul state, Brazil), with the present description of some remaining stands on Santa Maria river's flood plain, about $15 \mathrm{~km}$ south from the city.

Key words: Prosopis affinis, Phytogeography, municipality of Rosario do Sul, Rio Grande do Sul state, Brazil.

\section{INTRODUÇÃO}

Tema ainda não plenamente conhecido, a distribuição geográfica do inhanduvá apresentava duas vertentes na literatura sul-rio-grandense, havendo autores que limitavam a ocorrência natural da espécie ao município de Barra do Quaraí ou à planície sedimentar entre esta cidade e Uruguaiana, e outros que apontavam para uma área mais ampla, no oeste do Estado.

Entre os primeiros, Galvani (2003) afirmou, nas "Considerações Finais" de sua tese de doutorado, que a área do Parque Estadual do Espinilho constitui o "único ambiente de ocorrência" de Prosopis affinis e Prosopis nigra 4 no "estado do Rio Grande do Sul e no Brasil". Cabe salientar que o autor, na sequiência, comenta sobre a necessidade de maiores pesqui-

1 Recebido em 05-2-2011 e aceito para publicação em 30-2-2011.

2 Biólogo, MSc. Professor da Universidade da Região da Campanha (URCAMP - Alegrete). Doutorando do Programa de Pós-Graduação em Engenharia Florestal, UFSM.

3 Engenheiro Florestal, Dr. Professor Titular do Departamento de Ciências Florestais, UFSM. Bolsista de Produtividade em Pesquisa (CNPq - Brasil). sas sobre a origem geológica da "porção sudoeste" do Rio Grande, com vistas ao "esclarecimento da origem dessa singularidade" vegetacional $^{5}$.

$\mathrm{Na}$ corrente dos autores que consideravam uma área de ocorrência mais ampla para o inhanduvá, no oeste do Estado, incluem-se: Veloso \& Góes-Filho (1982), Marchiori et al. (1983, 1985A, 1985B) e Marchiori (2004).

Veloso \& Góes-Filho (1982) vincularam a presença do inhanduvá a solos aluviais próximos ao rio Uruguai, de Barra do Quaraí até Uruguaiana $^{6}$.

4 Destas espécies, apenas Prosopis nigra tem ocorrência restrita ao município de Barra do Quaraí, pois se encontra, apenas, nos chamados "blanqueales", isto é, em manchas com vegetação herbácea notavelmente reduzida, devido à elevada concentração de sais na superfície do solo. O inhanduvá (Prosopis affinis), embora também associado a formações sedimentares, ocorre em diferentes tipos de solo no oeste do Rio Grande do Sul.

5 GALVANI, F.R. Vegetação e aspectos ecológicos do Parque Estadual do Espinilho, Barra do Quaraí, RS. Porto Alegre: Universidade Federal do Rio Grande do Sul, 2003. Tese de Doutorado (Programa de Pós-Graduação em Botânica). p. 87.

6 VELOSO, H.B.; GÓES-FILHO, L. Fitogeografia brasileira - Classificação fisionômico-ecológica da vege- 
Marchiori et al. (1983, 1985A, 1985B) referiram a distribuição da espécie em "pontos isolados da Campanha do Sudoeste, notadamente ao longo da bacia do rio Ibicuî́". Em publicação posterior, Marchiori (2004) informou sobre a ocorrência natural do inhanduvá em alguns pontos da bacia do Ibicuí, inclusive no "município de São Vicente do Sul, sempre associado a depósitos aluviais" ${ }^{7}$.

O tema da distribuição geográfica do inhanduvá no Rio Grande do Sul ganhou, recentemente, a confirmação de duas novas ocorrências, em áreas disjuntas. A primeira delas, no município de Quaraí, encontra-se em lente sedimentar ao sul do Cerro do Jarau (Alves \& Marchiori, 2010). Em outro artigo, Marchiori et al. (2010) descreveram um parque natural próximo ao Cerro do Loreto, no município de São Vicente do Sul, documentando antiga referência. Mesmo sem esgotar o tema, tais novidades já bastam para contestar, com propriedade, a literatura que restringia a distribuição natural de Prosopis affinis ao município de Barra do Quaraí ou à planície aluvial adjacente ao rio Uruguai, em terras sul-rio-grandenses.

Ao registrar a existência de parques de inhanduvá em uma terceira área disjunta no Estado, o presente artigo visa a contribuir para o conhecimento da distribuição geográfica da espécie, bem como lançar novos olhares sobre a abrangência da Província do Espinhal no Rio Grande do Sul.

\section{DESCRIÇÃO DO PARQUE}

Situado na várzea ou planície aluvial ${ }^{8}$ do rio Santa Maria, município de Rosário do Sul, os fragmentos encontram-se à margem esquerda do referido rio e cerca de $15 \mathrm{~km}$ ao sul da cidade.

tação neotropical. Salvador: Projeto RADAMBRASIL, 1982. 80 p. (Boletim Técnico, Ser. Vegetação, v. 1).

7 MARCHIORI, J.N.C. Fitogeografia do Rio Grande do Sul. Campos sulinos. Porto Alegre: EST, 2004. p. 63.

8 Em linhas gerais, estes termos correspondem, grosso modo, a "planície de inundação" e a "planície de acumulação". Sobre este último termo, cabe informar que ele designa áreas planas que acompanham o curso de
De acordo com antigos moradores da região, tais parques estendiam-se por cerca de $10 \mathrm{~km}$ ao longo do rio, em área adjacente à mata ciliar $\mathrm{e}$ na transição para com o campo limpo, vegetação amplamente dominante nas coxilhas.

Apesar da exaustiva pesquisa realizada, encontrou-se apenas uma referência bibliográfica sobre esta valiosa árvore no município de Rosário do Sul. Trata-se de uma breve citação, datada de 1922, incluída por Alfredo Rodrigues da Costa no texto relativo à "Fazenda Curral de Pedras", em "O Rio Grande do Sul em todos os seus aspectos":

"Em diversos pontos do campo encontram-se também mattos da madeira de lei denominada inhanduvá" 9 .

$\mathrm{Na}$ toponímia regional também se encontra a "Fazenda Inhanduvá", propriedade da família Salles desde 1840 e que figura em diversos mapas, inclusive na carta "Rosário do Sul", editada pela Diretoria de Serviço Geográfico, do Ministério do Exército (escala 1:50,000) ${ }^{10}$, que serviu de base para a confecção da Figura 1. Resta informar que a Fazenda Curral de Pedras, anteriormente referida, dista $5 \mathrm{~km}$ ao sul da Fazenda Inhanduvá, situando-se ambas as sedes em colinas, à cavaleiro da planície de acumulação onde se encontram inhanduvás isolados e fragmentos remanescentes de um extenso parque que cedeu lugar a lavouras de arroz, em sua quase totalidade.

\footnotetext{
um rio, formadas a partir da deposição alúvio-colúvio, uma vez que concentra tanto o material erodido das regiões de interflúvio, transportado pela ação das águas superficiais, como os sedimentos deixados em períodos de transbordamento dos canais de drenagem (ALVES, F. da S. Estudos fitogeográficos na bacia hidrográfica do Arroio Lajeado Grande, oeste do Rio Grande do Sul. Santa Maria: UFSM, 2008. Dissertação (Programa de Pós-Graduação em Geografia e Geociências) - Universidade Federal de Santa Maria. f. 61-62).

9 COSTA, A.R. da. O Rio Grande do Sul em todos os seus aspectos. Porto Alegre: Livraria do Globo, 1922. v. 2. p. 380.

${ }^{10}$ Folha SH.21-Z-B-II-3 MI-2980/3.
} 


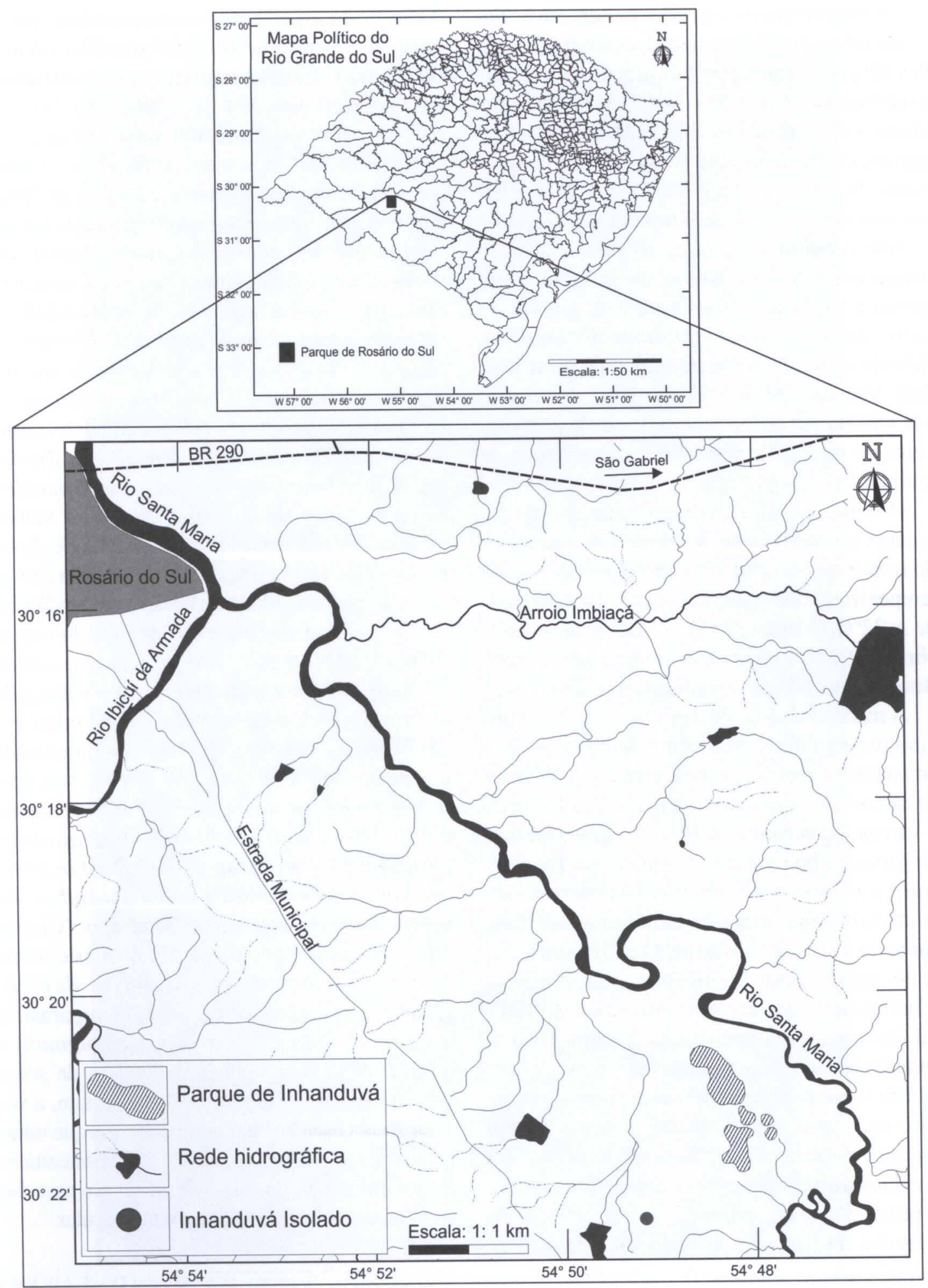

FIGURA 1 - Mapa de localização dos fragmentos de parque inhanduvá da várzea do rio Santa Maria, Rosário do Sul. 
Os fragmentos examinados pertencem à "Fazenda Inhanduvá", propriedade dos herdeiros do Sr. Miguel Henrique Nogueira de Salles. Dispersos em ampla área na várzea do rio Santa Maria, com altitude média de $100 \mathrm{~m}$, citam-se, apenas, como referência geográfica, as coordenadas de $30^{\circ} 21^{\prime} 44^{\prime \prime} \mathrm{S}$ e $54^{\circ} 48^{\prime} 09^{\prime \prime} \mathrm{W}$, correspondentes ao parque mais austral examinado.

Sob o ponto de vista geológico, a área do parque consiste de depósitos aluviais, com areia grossa a fina e sedimentos síltico-argilosos. $\mathrm{O}$ solo, definido como Planossolo Háplico Eutrófico Arênico (Streck et al., 2008) ou Unidade Vacacaí (Brasil, 1973), é o predominante nas várzeas da região, com relevo plano a suavemente ondulado, típicas de uma planície de inundação.

O clima, do tipo Cfa, apresenta chuvas regulares em todos os meses do ano, temperatura do mês mais frio entre $3-18^{\circ} \mathrm{C}$, e verões com temperatura média do mês mais quente superior a $22^{\circ} \mathrm{C}$ (Moreno, 1961). De acordo com Nimer (1977), corresponde ao tipo Mesotérmico Brando Super-Úmido, sem estação seca.

A madeira do inhanduvá, famosa por sua durabilidade natural, é frequentemente observada nos moirões e palanques de cerca que dividem os campos da propriedade (Figura 2A). Em toda a várzea, os inhanduvás se encontram melhor preservados no chamado "Piquete dos Touros", que é o mais extenso dos fragmentos, restando os demais, bem como os indivíduos isolados, em meio a lavouras de arroz. O cultivo da terra, junto aos referidos fragmentos, compromete a sobrevivência das árvores pela alteração radical das condições ambientais (Figura 2B, C), levando à morte paulatina das mesmas.

Em todos os fragmentos examinados observam-se, apenas, inhanduvás adultos e sem espaçamento regular, destacando-se alguns indivíduos de dimensões notáveis para a espécie (Figura 3), à semelhança do observado na Cabanha do Loreto ${ }^{11}$, em São Vicente do Sul.

${ }^{11}$ MARCHIORI, J.N.C.; DURLO, M.A.; ALVES, F. da S. O inhanduvá (Prosopis affinis Spreng.) no Rio Gran-
Além desta espécie dominante, também participam do estrato arbóreo: a coronilha (Scutia buxifolia), o branquilho (Sebastiania commersoniana), o toropi (Sapium haematospermum), a unha-de-gato (Senegalia bonariensis), o pau-de-junta (Coccoloba argentinensis), a pitangueira (Eugenia uniflora) e o gerivá (Syagrus romanzoffiana). Das lianas, destacam-se o maracujá-azul (Passiflora caerulea) e o cipó-timbó (Paullinia elegans). Das epífitas, salientam-se três pteridófitas (Microgramma mortoniana; Pleopeltis pleopeltifolia; Pleopeltis squalida), três cravosdo-mato (Tillandsia aeranthos; Tillandsia recurvata; Tillandsia tricholepis), bem como uma orquídea (Oncidium bifolium), a barba-depau (Usnea barbata) e Lepismium lumbricoides, cactácea especialmente abundante em velhos inhanduvás. No estrato herbáceo, além de diversas espécies de gramíneas, chama atenção a ervada-vida (Heimia salicifolia), por sua abundância.

Comparado ao parque da Cabanha do Loreto (São Vicente do Sul), a vegetação em estudo distingue-se, principalmente, pela presença de algumas espécies imigradas da mata ciliar em sua estrutura. No confronto com os parques de inhanduvá de Barra do Quaraí, por sua vez, destaca-se a ausência do algarrobo (Prosopis nigra), do quebracho (Aspidosperma quebrachoblanco), da cina-cina (Parkinsonia aculeata), da sombra-de-touro (Acanthosyris spinescens), de dois cactos terrestres (Cereus hildmannianus, Opuntia elata), de dois cravosdo-mato chaquenhos (Tillandsia duratii, Tillandsia ixioides), de algumas hemiparasitas (Ligaria cuneifolia, Eubrachion ambiguum) e de uma pequena gramínea indicadora de solos salinos (Tripogon spicatus). Mesmo assim, a vegetação em estudo é um verdadeiro parque natural de inhanduvá, posto que formado, basicamente, por indivíduos de Prosopis affinis em associação inequiânea e sem espaçamento regular.

de do Sul. 4 - Aspectos botânico-vegetacionais e morfométricos do Parque do Loreto, São Vicente do Sul. Balduinia, Santa Maria, n. 26, p. 8-18, 2011. 

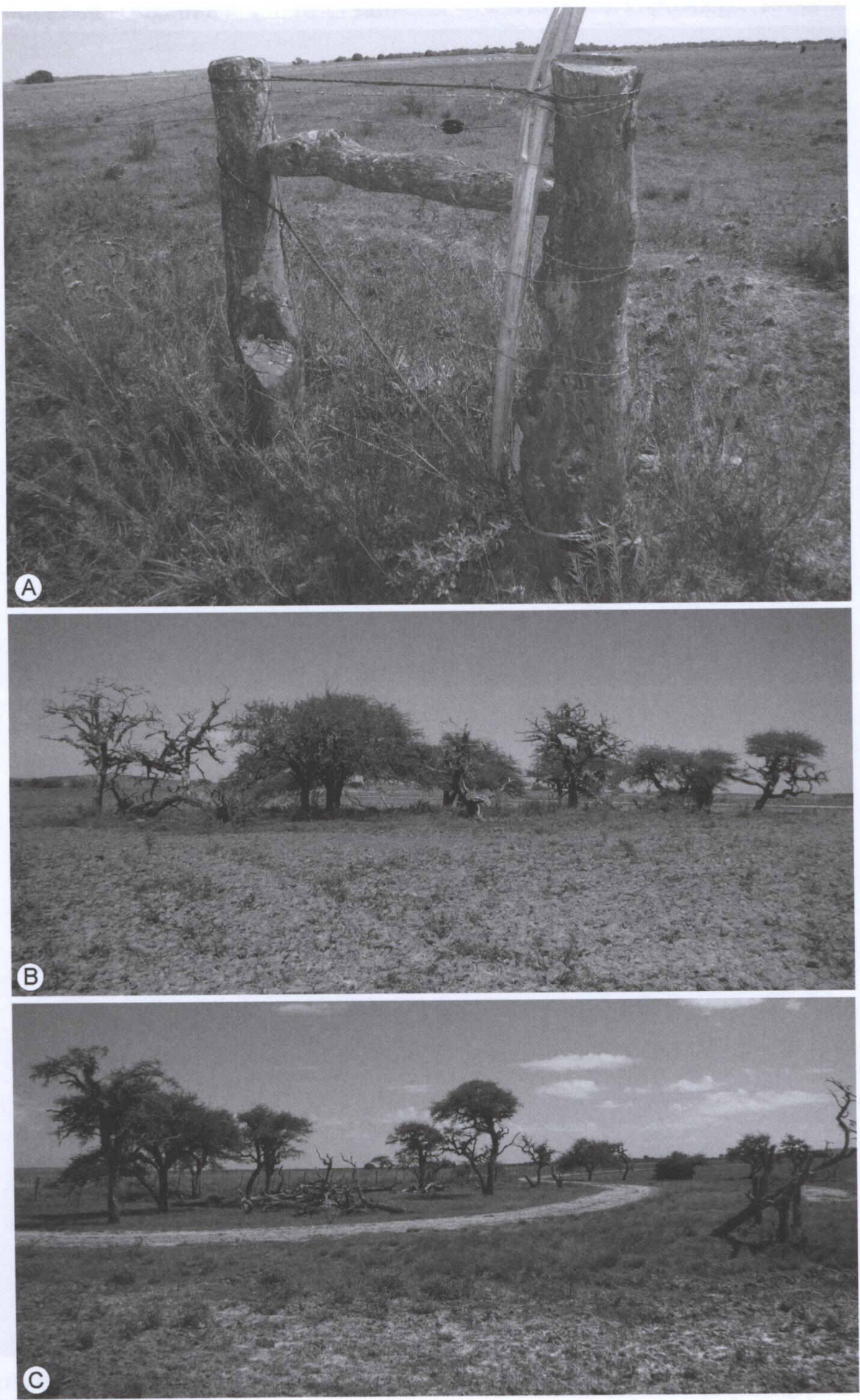

FIGURA 2 - O Inhanduvá na várzea do rio Santa Maria, Rosário do Sul. A - Canto de cerca, com moirões e retranca feitos com madeira de inhanduvá. B - Fragmento de parque, ameaçado pelo avanço da área agrícola. C - Troncos de inhanduvá mortos e empilhados, junto a fragmento remanescente de parque. 

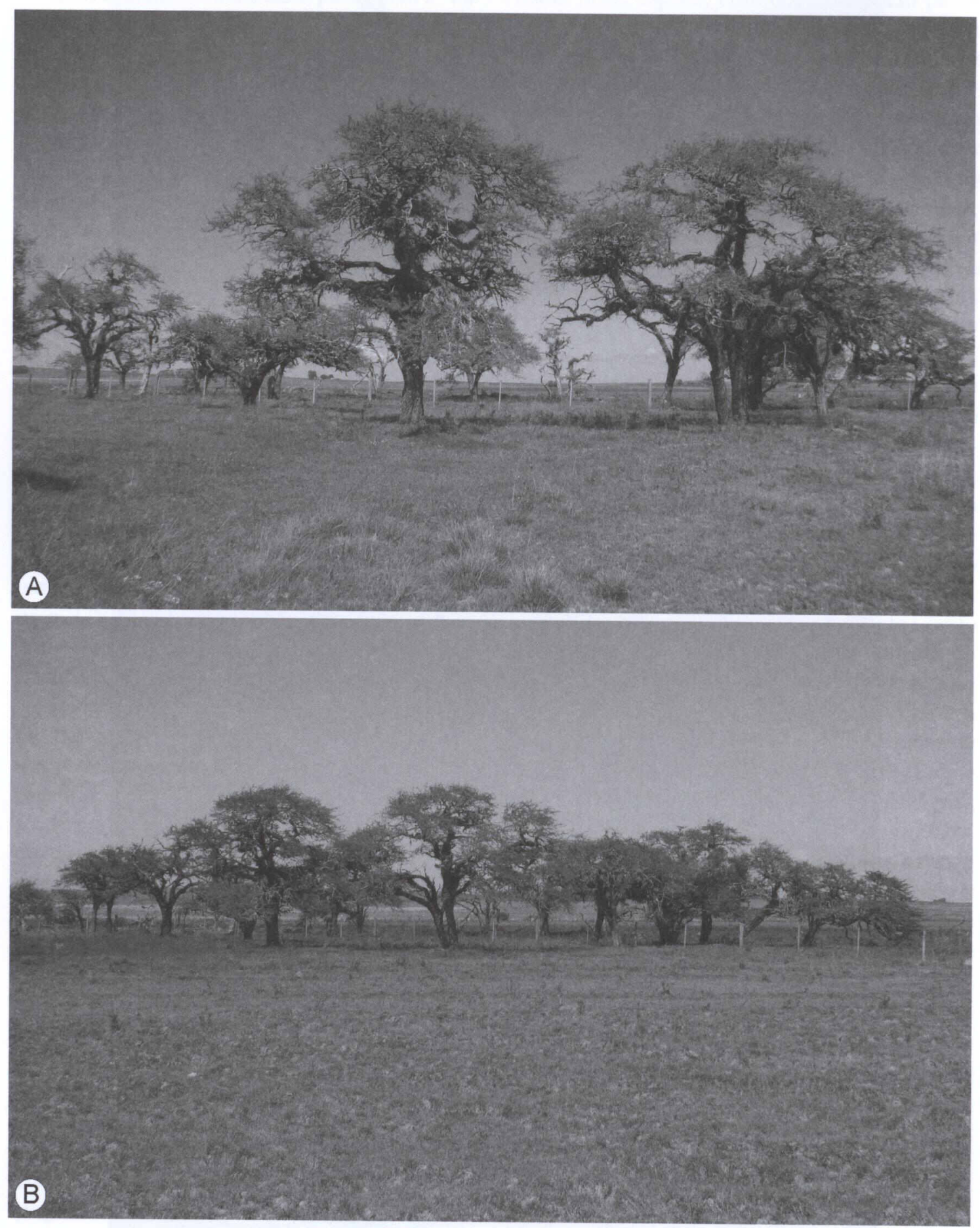

FIGURA 3 - Dois aspectos dos parques de inhanduvá de Rosário do Sul. A - Indivíduos de grandes dimensões. B - Aspecto geral de um fragmento de parque. 
A respeito de sua origem natural, resta salientar que esta interpretação é suportada tanto pela tradição oral como por referência bibliográfica datada do primeiro quartel do século XX.

Em todas as ocorrências de Prosopis affinis no Rio Grande do Sul, até o momento conhecidas, a espécie está associada, invariavelmente, a formações sedimentares, mas não a um tipo específico de solo, como afirmado por Galvani $(2003)^{12}$ e Galvani \& Baptista $(2003)^{13}$.

Situado $70 \mathrm{~km}$ ao sul do parque do Loreto (São Vicente do Sul), $170 \mathrm{~km}$ a leste do Parque do Jarau (Quaraí), e $200 \mathrm{~km}$ a leste dos parques de inhanduvá do Pontal do Quaraí (Barra do Quaraí), o presente registro da ocorrência natural de Prosopis affinis em Rosário do Sul amplia, consideravelmente, a distribuição geográfica da espécie no Rio Grande do Sul. A estreita vinculação do inhanduvá com formações sedimentares, bem como as disjunções verificadas a leste do Planalto da Campanha (parques do Loreto e de Rosário do Sul), reforçam o caráter relitual dos mesmos, bem como sinalizam o vale do rio Ibicuí como rota imigratória, a partir do extremo oeste do Estado.

\section{REFERÊNCIAS BIBLIOGRÁFICAS}

ALVES, F. da S. Estudos fitogeográficos na bacia hidrográfica do arroio Lajeado Grande, oeste do Rio Grande do Sul. Santa Maria: Universidade Federal de Santa Maria, 2008. 106 f. Dissertação (Programa de Pós-Graduação em Geografia e Geociências).

ALVES, F. da S.; MARCHIORI, J.N.C. O inhanduvá (Prosopis affinis Spreng.) no Rio Grande do Sul. 2 - Ocorrência natural na região do Jarau, Quaraí. Balduinia, Santa Maria, n. 25, p. 1-9, 2010.

BRASIL. Ministério da Agricultura. Departamento Nacional de Pesquisa Agropecuária. Divisão Pedológica. Levantamento de reconhecimento dos solos do Estado do Rio Grande do Sul. Recife, 1973. 471 p. (DNPEA. Boletim Técnico, 30). COSTA, A.R. da. O Rio Grande do Sul em todos os

${ }^{12}$ GALVANI, 2003. Op. cit., p. 63.

${ }^{13}$ GALVANI, F.R.; BAPTISTA, L.R. de M. Flora do Parque Estadual do Espinilho - Barra do Quaraí/RS. Revista da FZVA, Uruguaiana, v. 10, n. 1, p. 49-50. seus aspectos. Porto Alegre: Livraria do Globo, 1922. v. 2. 524 p.

GALVANI, F.R. Vegetação e aspectos ecológicos do Parque Estadual do Espinilho, Barra do Quaraí, RS. Porto Alegre: Universidade Federal do Rio Grande do Sul, 2003. 132 f. Tese de Doutorado (Programa de Pós-Graduação em Botânica).

GALVANI, F.R.; BAPTISTA, L.R. de M. Flora do Parque Estadual do Espinilho - Barra do Quaraí/ RS. Revista da FZVA, Uruguaiana, v. 10, n. 1, p. 42-62, 2003.

MARCHIORI, J.N.C. Fitogeografia do Rio Grande do Sul. Campos Sulinos. Porto Alegre: EST, 2004. 110 p.

MARCHIORI, J.N.C.; ALVES, F. da S.; PAZ, E.A. O inhanduvá (Prosopis affinis Spreng.) no Rio Grande do Sul. 3 - Parque da Cabanha do Loreto, São Vicente do Sul. Balduinia, Santa Maria, n. 25 , p. 22-31, 2010.

MARCHIORI, J.N.C.; DURLO, M.A.; ALVES, F. da S. O inhanduvá (Prosopis affinis Spreng.) no Rio Grande do Sul. 4 - Aspectos botânicovegetacionais e morfométricos do Parque do Loreto, São Vicente do Sul. Balduinia, Santa Maria, n. 26, p. 8-18, 2011.

MARCHIORI, J.N.C.; LONGHI, S.J.; GALVÃO, L. O gênero Prosopis L. (Leguminosae Mimosoideae) no Rio Grande do Sul. Ciência e Natura, Santa Maria, n. 5, p. 171-177, 1983.

MARCHIORI, J.N.C.; LONGHI, S.J.; GALVÃO, L. Composição florística e estrutura do parque de inhanduvá no Rio Grande do Sul. Rev. Centro de Ciências Rurais, Santa Maria, v. 15, n. 4, p. 319-334, 1985A.

MARCHIORI, J.N.C.; LONGHI, S.J.; GALVÃO, L. Estrutura fitossociológica de uma associação natural de parque inhanduvá com quebracho e cina-cina, no Rio Grande do Sul. Ciência e Natura, Santa Maria, n. 7, p. 147-162, 1985B.

MORENO, J.A. Clima do Rio Grande do Sul. Porto Alegre: Secretaria da Agricultura - Diretoria de Terras e Colonização, 1961. 42 p.

NIMER, R. Clima. Geografia do Brasil. Região Sul. Rio de Janeiro: IBGE, 1977. p. 35-79.

STRECK, E.V.; KÄMPF, N.; DALMOLIN, R.S.D.; KLAMT, E.; NASCIMENTO, P.C. do; SCHNEIDER, P.; GIASSON, E.; PINTO, L.F.S. Solos do Rio Grande do Sul. Porto Alegre: EMATER/RS - ASCAR, 2008. 222p.

VELOSO, H.P.; GÓES-FILHO, L. Fitogeografia brasileira. Classificação fisionômico-ecológica da vegetação neotropical. Salvador: Projeto RADAMBRASIL, 1982. 80 p. (Boletim Técnico, Ser. Vegetação, v. 1). 